\title{
Pesquisa de anticorpos anti-Rickettsia rickettsii em eqüinos do Centro de Controle de Zoonoses do município de São Paulo (CCZ/SP)
}

Jonas MORAES-FILHO ${ }^{1}$

Maurício Claudio HORTA ${ }^{1}$

Richard de Campos

PACHECO $^{1}$

Marly Matiko MAEDA²

Arquimedes GALANO ${ }^{2}$

Maria Lucia de OLIVEIRA²

Lucia Eiko Oishi YAI ${ }^{2}$

Marcelo Bahia LABRUNA ${ }^{1}$

\section{Correspondência para:}

Marcelo Bahia Labruna, Departamento de Medicina Veterinária Preventiva e Saúde Animal, Faculdade de Medicina Veterinária eZootecnia, Universidade de São Paulo, Av. Prof. Orlando Marques de Paiva 87, 05508-270, São Paulo, SP, Brasil. E-mail: labruna@usp.br

Recebido para publicação: 13/11/2007 Aprovado para publicação: 28/08/2008

\author{
1 - Departamento de Medicina Veterinária Preventiva e Saúde Animal da \\ Faculdade de Medicina Veterinária e Zootecnia da Universidade de São \\ Paulo, São Paulo - SP \\ 2 - Centro de Controle de Zoonoses, Prefeitura Municipal de São Paulo, São \\ Paulo - SP
}

\section{Resumo}

A Febre Maculosa Brasileira (FMB) é uma zoonose transmitida por pelo menos duas espécies de carrapatos: Amblyomma cajennense e Amblyomma aureolatum. Os eqüinos assumem um importante papel de sentinela da FMB em áreas onde o carrapato vetor é o $A$. cajennense, por ser considerado hospedeiro primário dessa espécie de carrapato. $\mathrm{O} A$. aureolatum, cujos hospedeiros primários são aves, alguns roedores silvestres e canídeos, é incriminado como vetor da doença na região da Grande São Paulo. Este trabalho objetivou pesquisar a presença de anticorpos contra Rickettsia rickettsii, agente da FMB, em eqüinos encaminhados ao Centro de Controle de Zoonoses do município de São Paulo (CCZ/SP) no período de 2003 a 2005. Após coleta de sangue, o soro obtido pela centrifugação foi submetido à reação de imunofluorescência indireta (RIFI) e os animais foram considerados positivos quando as amostras de soro apresentaram títulos $\geq 64$. Durante os três anos, foram testados 363 amostras pela RIFI, sendo que 64 se mostraram reagentes: 6 (2003), 16 (2004) e 42 (2005). Os títulos finais variaram de 64 a 1.024 . Os resultados obtidos demonstram uma baixa porcentagem de animais reagentes $(17,6 \%)$ quando comparados com dados de literatura de áreas endêmicas para FMB onde o vetor é o $A$. cajennense, sugerindo não ser essa espécie responsável pela transmissão da doença na área de estudo.

\section{Introdução}

Rickettsia spp são bactérias intracelulares obrigatórios, pertencentes à família Rickettsiaceae e à ordem Rickettsiales. ${ }^{1}$ As espécies deste gênero estão classicamente divididas em dois grupos, baseados nos padrões antigênicos, moleculares e ecológicos: i. grupo do tifo (GT), composto pelas espécies Rickettsia prowazekii e Rickettsia typhi, transmitidas por piolhos e pulgas, respectivamente; ii. grupo da febre maculosa (GFM), o qual está composto por mais de 23 espécies válidas, das quais há pelo menos doze espécies que comprovadamente causam infecções no homem. A transmissão da grande maioria
Palavras-chave:

Rickettsia rickettsii.

Imunofluorescência Indireta. Eqüinos.

São Paulo. das espécies do GFM está associada a carrapatos, com exceção da Rickettsia felis e Rickettsia akari, associadas a pulgas e pequenos ácaros, respectivamente. Outras espécies de riquétsias, tais como Rickettsia bellii e Rickettsia canadensis não estão inseridas em nenhum destes dois grupos. ${ }^{2}$

No Brasil, a doença causada por riquétsias do GFM é denominada Febre Maculosa Brasileira (FMB) e a Rickettsia rickettsii tem sido incriminada como principal agente etiológico. Casos confirmados de FMB tem sido relatados em determinadas áreas dos estados da região Sudeste, ${ }^{3,4,5,6}$ além da $\mathrm{Bahia}^{7}$ e, mais recentemente, nos estados da região Sul, especialmente em Santa 
Catarina, na região de Blumenau ${ }^{8}$. A FMB causada por $R$. rickettsii é considerada, indubitavelmente, como uma das doenças de maior letalidade no Estado de São Paulo. ${ }^{9}$

O carrapato Amblyomma cajennense é o vetor mais comum da FMB, ${ }^{10,11}$ sendo a principal espécie de carrapato que parasita seres humanos no centro sul brasileiro. Eqüinos, capivaras e antas são considerados os principais hospedeiros para todos os estágios parasitários do $A$. cajennense no Brasil. ${ }^{12}$ Conseqüentemente, os eqüinos assumem um importante papel de sentinela da FMB em áreas onde o carrapato vetor é o $A$. cajennense..$^{13}$ No entanto, na região da Grande São Paulo, onde 31 casos de FMB foram confirmados de 2003 a $2006^{14}$, o carrapato Amblyomma aureolatum tem sido incriminado como principal vetor da $\mathrm{FMB}^{15,16,17}$. Este carrapato possui como hospedeiros primários: aves e pequenos roedores para larvas e ninfas; e canídeos (especialmente cães domésticos) para os carrapatos adultos. ${ }^{18}$ Desta forma, a ecologia da FMB na região metropolitana de São Paulo tem sido considerada distinta das demais regiões do estado, onde o vetor incriminado é $A$. cajennense.

Os eqüinos são sentinelas para FMB em áreas com potencial de transmissão pelo A. cajennense. A região metropolitana de São Paulo possui um grande número de eqüinos em diversos locais, os quais estão na maioria das vezes, parasitados por $A$. cajennense (dados não publicados do CCZ/SP). Para avaliar a situação sorológica da FMB, este trabalho objetivou pesquisar a presença de anticorpos anti-R. rickettsii em amostras de soro de eqüinos encaminhados ao Centro de Controle de Zoonoses do município de São Paulo (CCZ/SP), no período de 2003 a 2005.

\section{Material e Método}

Local de Estudo: Este estudo foi realizado com eqüinos provenientes de 70 bairros do município de São Paulo, englobando todas as regiões geopolíticas do Município. Os animais foram encaminhados ao CCZ/SP no período de 2003 a 2005.

Colheita de sangue: As amostras de sangue foram colhidas por punção venosa, com auxílio de uma agulha e tubos de vidro estéreis, e transportadas em temperatura ambiente para o laboratório e, posteriormente centrifugadas $(1.500 \mathrm{~g}$ por 10 minutos) para obtenção do soro, os quais foram aliquotados em microtubos, separados e congelados $\mathrm{a}-20^{\circ} \mathrm{C}$ até serem testados.

Reação de Imunofluorescência Indireta (RIFI): A RIFI foi realizada segundo o protocolo descrito por Horta et al. ${ }^{19}$ e as amostras foram consideradas sororeagentes quando apresentavam títulos $>$ 64. Os soros foram diluídos a partir de 1:64 em PBS $(0,1 \mathrm{M}, \mathrm{pH} 7,2)$ e $20 \mathrm{ml}$ do soro diluído foi aplicado sobre cada pocinho das lâminas contendo antígenos brutos de R. rickettsii cepa Taiaçu, proveniente de isolado de carrapato $A$. aureolatum. ${ }^{20}$ As lâminas foram incubadas em câmara úmida a $37^{\circ} \mathrm{C}$ por 30 minutos. As lâminas foram lavadas com solução de PBS $(0,1$ M, pH 7,2) e mantidas em uma cuba com a mesma solução durante 15 minutos, por duas vezes. Após secarem, foram incubadas a $37^{\circ} \mathrm{C}$ por 30 minutos com conjugado IgG coelho anti$\mathrm{IgG}$ de eqüino (Sigma Diagnostics, St. Luis, Mo) acoplado com isotiocianato de fluoresceína na diluição de 1:100. As lâminas foram lavadas como descrito anteriormente e coradas em solução de PBS $(0,1 \mathrm{M}, \mathrm{pH}$ $7,2)$, contendo 0,2\% de azul de Evans. Após completamente secas, as lâminas foram montadas com glicerina tamponada e lamínula para posterior leitura em microscópio equipado com luz ultravioleta (Olympus BX60, Japan) com objetiva de $40 \mathrm{X}$.

\section{Resultados}

O presente trabalho avaliou soros de 363 eqüinos pela RIFI, sendo que $64(17,6 \%)$ se mostraram reagentes a $R$ rickettsii: $6 / 77$ (7,8\%) em 2003, 16/110 (14,5\%) em 2004 e $42 / 176(23,9 \%)$ em 2005. Os títulos finais variaram de 64 a 1.024, sendo 11 amostras 
de soro para o título final de $64 ; 12$ amostras para 128; 15 amostras para 256; 14 amostras para 512 e 12 amostras para 1024.

Dos 70 bairros amostrados, 36 apresentaram pelo menos um animal reagente pela RIFI (Tabela 1). Não foram encontrados animais reagentes em 34 bairros: Água Rasa ( $\mathrm{n}=4$ eqüinos testados), Aricanduva (3), Barra Funda (1), Belém (1), Brasilândia (4), Carrão (5), Casa Verde (1), Cidade Ademar (7), Itaim Paulista (2), Jabaquara (5), Jardim Helena (3), Lajeado (1), Lapa (1), Liberdade (1), Limão (1),
Mooca (1), Morumbi (4), Penha (3), Perus (2), Raposo Tavares (2), Rio Pequeno (6), Sacomã (2), São Mateus (1), Sapopemba (3), Socorro (4), Tatuapé (3), Tucuruvi (2), Vila Formosa (1), Vila Guilherme (1), Vila Jacuí (2), Vila Leopoldina (4), Vila Matilde (2), Vila Medeiros (3), Vila Sônia (2). A tabela 1 mostra os bairros do município que apresentam pelo menos um eqüino reativo ao antígeno de $R$. rickettsii, com títulos de anticorpos $\geq 64$ pela RIFI, durante o período estudado.

Em relação à distribuição das amostras positivas por regiões do município,

Tabela 1 - Bairros do município de São Paulo que apresentaram pelo menos um eqüino reativo ao antígeno de Rickettsia rickettsii, com títulos de anticorpos $\geq 64$ pela reação de imunofluorescência indireta (RIFI) no período de 2003 a 2005

\begin{tabular}{|c|c|c|c|c|c|}
\hline \multirow{2}{*}{ Bairro } & \multirow{2}{*}{$\begin{array}{l}\text { Região da } \\
\text { Cidade }\end{array}$} & \multicolumn{3}{|c|}{$\mathbf{N}^{0}$ de eqüinos reativos na RIFI / $\mathbf{N}^{0}$ de eqüinos testados } & \multirow{2}{*}{ Total } \\
\hline & & 2003 & 2004 & 2005 & \\
\hline Cachoeirinha & \multirow{7}{*}{ NORTE } & $0 / 2$ & $1 / 2$ & $0 / 4$ & $1 / 8$ \\
\hline Freguesia do Ó & & $0 / 1$ & $1 / 6$ & $0 / 0$ & $1 / 7$ \\
\hline Jaraguá & & $1 / 3$ & $0 / 4$ & $0 / 4$ & 1/11 \\
\hline Mandaqui & & $0 / 3$ & $0 / 4$ & $1 / 2$ & $1 / 9$ \\
\hline Pirituba & & $0 / 2$ & $2 / 5$ & $0 / 0$ & $2 / 7$ \\
\hline Santana & & $0 / 0$ & $0 / 3$ & $1 / 4$ & $1 / 7$ \\
\hline Tremembé & & $0 / 0$ & $0 / 2$ & $1 / 3$ & $1 / 5$ \\
\hline Campo Grande & \multirow{15}{*}{ SUL } & $1 / 3$ & $0 / 0$ & $0 / 1$ & $1 / 4$ \\
\hline Campo Limpo & & $0 / 0$ & $0 / 5$ & $4 / 8$ & $4 / 13$ \\
\hline Capão Redondo & & $1 / 1$ & $0 / 6$ & $0 / 3$ & $1 / 10$ \\
\hline Cidade Dutra & & $0 / 4$ & $2 / 5$ & $4 / 12$ & $6 / 21$ \\
\hline Cursino & & $1 / 2$ & $0 / 1$ & $0 / 0$ & $1 / 3$ \\
\hline Grajaú & & $0 / 0$ & $0 / 2$ & $4 / 21$ & $4 / 23$ \\
\hline Ipiranga & & $0 / 0$ & $1 / 4$ & $1 / 2$ & $2 / 6$ \\
\hline Jardim Ângela & & $0 / 0$ & $1 / 6$ & $2 / 6$ & $3 / 12$ \\
\hline Jardim São Luiz & & $1 / 7$ & $0 / 5$ & $3 / 20$ & $4 / 32$ \\
\hline Parelheiros & & $0 / 0$ & $2 / 7$ & $3 / 10$ & $5 / 17$ \\
\hline Pedreira & & $0 / 0$ & $0 / 1$ & $2 / 4$ & $2 / 5$ \\
\hline Santo Amaro & & $0 / 1$ & $2 / 2$ & $0 / 1$ & $2 / 4$ \\
\hline Saúde & & $0 / 0$ & $0 / 0$ & $1 / 1$ & $1 / 1$ \\
\hline Vila Andrade & & $0 / 0$ & $0 / 0$ & $1 / 5$ & $1 / 5$ \\
\hline Vila Mariana & & $0 / 0$ & $0 / 0$ & $1 / 1$ & $1 / 1$ \\
\hline Cangaíba & \multirow{6}{*}{ LESTE } & $0 / 1$ & $0 / 0$ & $1 / 3$ & $1 / 4$ \\
\hline Cidade Lider & & $0 / 2$ & $0 / 1$ & $2 / 4$ & $2 / 7$ \\
\hline Cidade Tiradentes & & $0 / 2$ & $0 / 0$ & $2 / 6$ & $2 / 8$ \\
\hline Iguatemi & & $0 / 0$ & $0 / 0$ & $1 / 2$ & $1 / 2$ \\
\hline Itaquera & & $1 / 1$ & $0 / 2$ & $0 / 0$ & $1 / 3$ \\
\hline São Miguel & & $0 / 1$ & $0 / 0$ & $1 / 3$ & $1 / 4$ \\
\hline Alto de Pinheiros & \multirow{6}{*}{ OESTE } & $0 / 0$ & $0 / 0$ & $1 / 1$ & $1 / 1$ \\
\hline Butantã & & $0 / 2$ & $2 / 4$ & $0 / 0$ & $2 / 6$ \\
\hline Itaim Bibi & & $0 / 0$ & $0 / 0$ & $1 / 1$ & $1 / 1$ \\
\hline Jaguaré & & $0 / 0$ & $1 / 3$ & $1 / 3$ & $2 / 6$ \\
\hline Jardim Paulista & & $0 / 0$ & $0 / 0$ & $1 / 4$ & $1 / 4$ \\
\hline Pinheiros & & $0 / 1$ & $1 / 2$ & $0 / 1$ & $1 / 4$ \\
\hline Brás & \multirow{2}{*}{ CENTRAL } & $0 / 0$ & $0 / 0$ & $1 / 1$ & $1 / 1$ \\
\hline República & & $0 / 0$ & $0 / 0$ & $1 / 1$ & $1 / 1$ \\
\hline
\end{tabular}


destacam-se as regiões Sul e Oeste, com $21,2 \%$ e $20,0 \%$ de animais sororeagentes, respectivamente. Nas regiões Norte e Leste, as proporções de animais sororeagentes oscilaram entre $12,1 \%$ e $12,7 \%$. Na região Central, a proporção de sororeagentes foi de 66,6\% (Figura 1).

\section{Discussão e Conclusões}

Os resultados obtidos demonstram uma baixa porcentagem de animais reagentes à $R$. rickettsii pela RIFI $(17,6 \%)$ quando comparados com dados observados por Lemos et al. ${ }^{21}$, Horta et al. ${ }^{19}$ e Horta et al. ${ }^{22}$ em áreas endêmicas para FMB do interior de São Paulo, onde foram encontrados $77,8 \%, 56,5 \%$ e $72,9 \%$ respectivamente, de eqüinos sororeagentes. Nestas localidades, o carrapato $A$. cajennense é incriminado como o principal vetor da FMB. ${ }^{19,21,22}$ Essas regiões têm apresentado um padrão soroepidemiológico caracterizado por uma alta freqüência de eqüinos sororeagentes, acompanhada de uma freqüência baixa de cães soropositivos e uma baixa ou ausente presença de humanos sororeagentes. ${ }^{19,21}$ Os baixos títulos observados no presente trabalho são semelhantes aos encontrados por Cardoso et al. ${ }^{23} \mathrm{em}$ Minas Gerais, em uma região sem registro de casos de FMB nos últimos 12 anos, colocando o município em um nível de baixa transmissão, indicando uma infecção antiga pela $R$. rickettsii ou por outra riquétsia do GFM. Deve-se destacar também que embora os animais do presente estudo tenham sido resgatados ou encaminhados para o CCZ do município de São Paulo, a procedência desses animais não é totalmente conhecida, sendo que a maioria é constituída principalmente por animais errantes.

Analisando os resultados obtidos por bairros, os valores encontrados na periferia representam a maioria $(61,1 \%)$ dos resultados positivos encontrados. Em relação à distribuição dos animais reagentes na cidade de São Paulo, destacam-se as regiões das Zonas Sul e Oeste, onde a presença de carrapatos em áreas verdes é maior, assim como o número de eqüinos utilizados para o trabalho e de animais errantes nesta área, contribuindo para a proliferação do vetor. $\mathrm{Na}$ região Central, a proporção de sororeagentes foi de $66,6 \%$; no entanto,

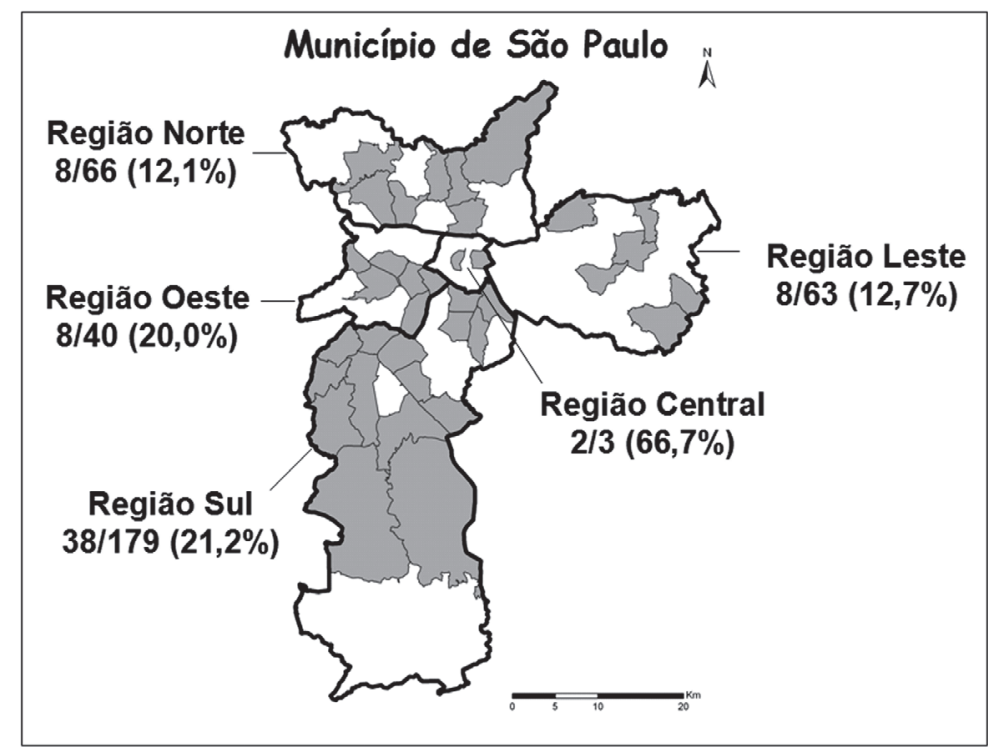

Figura 1 - Número de eqüinos encaminhados ao Centro de Conrole de Zoonoses/SP, submetidos à reação de imunofluorescência indireta (RIFI) e que apresentaram anticorpos anti-Rickettsia rickettsii, de acordo com as regiões do Município de São Paulo, no período de 2003 a 2005 [número de animais positivos / número de animais testados $(\%)]$. Em destaque, os bairros onde foram encontrados pelo menos um eqüino reagentes à RIFI 
apenas três animais dessa região foram testados. No período de 2002 a 2005, foram confirmados cinco casos de FMB no Município de São Paulo ${ }^{14}$, sendo que os locais prováveis de infecção foram nos arredores do parque do Estado, na região Sul do município (Vera Pinto Arantes, comunicação pessoal, COVISA, Secretaria de Saúde do Município de São Paulo), área com presença de $A$. aureolatum..$^{15}$ Além disso, a região Sul do município encontra-se próxima a outros municípios da Grande São Paulo onde ocorreram notificações de casos de FMB nos últimos anos. ${ }^{14}$ Nesses locais onde o $A$. aureolatum está incriminado como principal vetor, verifica-se uma baixa prevalência de eqüinos sororeagentes e uma alta prevalência de cães soropositivos. Desta forma, nessas áreas, os cães atuam como sentinelas da FMB. ${ }^{15,16,17}$

Como o $A$. aureolatum não parasita eqüinos, o perfil sorológico desses animais para R. rickettsii está intimamente relacionado ao parasitismo por carrapatos $A$. cajennense infectados. Os resultados do presente trabalho indicam que há baixa circulação de $R$. rickettsii entre carrapatos $A$. cajennense no Município de São Paulo, uma vez que a maioria dos animais foram não reativos em todas as regiões amostradas. Contudo, o parasitismo por carrapatos especificamente nos animais testados não foi avaliado. Alternativamente, os títulos anti- $R$. rickettsii observados nos eqüinos poderiam ser devido a reações cruzadas com outras espécies de Rickettsia do GFM, que por ventura infectaram os eqüinos, já que as reações sorologias cruzadas entre Rickettsia spp do GFM é um bastante comum. ${ }^{1,2}$ A baixa porcentagem de eqüinos reagentes $(17,6 \%)$ no município de São Paulo, quando comparados com eqüinos de áreas endêmicas para FMB onde o vetor é o $A$. cajennense, sugere não ser essa espécie responsável pela transmissão da doença na área de estudo.

\section{Agradecimentos}

À Fundação de Amparo a Pesquisa do Estado de São Paulo (FAPESP) e ao Conselho Nacional de Desenvolvimento Científico e Tecnológico $(\mathrm{CNPq})$ pelo auxílio financeiro para o desenvolvimento do trabalho.

\section{Detection of antibodies against Rickettsia rickettsii in equines of the Zoonosis Control Center of São Paulo Municipality (CCZ/SP)}

\section{Abstract}

Brazilian Spotter Fever (BSF) is a tick-borne zoonosis transmitted by at least two tick species: Amblyomma cajennense and Amblyomma aureolatum. In areas where the tick vector is $A$. cajennense, equines are important for being considered primary hosts of this tick species. $A$. aureolatum, whose primary hosts include birds, some rodent species, and dogs, is incriminated as vector in the metropolitan region of São Paulo city. This work aimed to detect antibodies reactive to Rickettsia rickettsii in equines sent to the Zoonosis Control Center of São Paulo Municipality (CCZ/SP) during the period from 2003 to 2005. After blood collection, sera were obtained by centrifugation and tested by the indirect immunofluorescence assay (IFA) and animals were considered positive if sera presented titers $\geq 64$. During three years, 363 equine sera sent to CCZ/SP, were tested by IFA, and 64 showed reactive: 6 (2003), 16 (2004) and 42 (2005). The end-point titers varied from 64 to 1.024 . The results demonstrate a low percentage $(17.6 \%)$ of reactive animals, when compared with literature data from BSFendemic areas where $A$. cajennense is the vector, suggesting that this tick is not a main vector in the study area.
Key words:

Rickettsia rickettsii. Indirect immunofluorescence assay. Equine.

São Paulo. 


\section{Referências}

1 RAOULT, D.; ROUX, V. Rickettsioses as paradigms of new or emerging infectious diseases. Clinical Microbiology Reviews, v. 10, n. 4, p. 694-719, 1997.

2 YU, X. J.; WALKER, D. H. The order Rickettsiales. In: DWORKIN, M. (Ed.). The Prokaryotes: an evolving electronic resource for the microbiology community. 3rd ed. New York: Springer-Velag, 2003. Disponível em: < http://link.springer-ny.com/link/service/books/ 10125 >. Acesso em: 17 abr. 2004.

3 GALVÃO, M. A. M.; CALIC, S. B.; CHAMONE, C. B.; MAFRA, S. C. L.; CESARINO FILHO, G.; OLANO, J. P.; WALKER, D. H. Spotted fever rickettsiosis in Coronel Fabriciano, Minas Gerais State. Revista da Sociedade Brasileira de Medicina Tropical, v. 36, p. 479-481, 2003.

4 LEMOS, E. R. S.; ALVARENGA, F. B. F.; CINTRA, M. L.; RAMOS, M. C.; PADDOCK, C. D.; FEREBEE, T. L.; ZAKI, S. R.; FERREIRA, F. C. C.; RAVAGNANI, R. C.; MACHADO, R. D.; GUIMARÃES, M. A. A. M. COURA, J. R. Spotted fever in Brazil: a seroepidemiological study and description of clinical cases in an endemic area in the state of São Paulo. American Journal of Tropical Medicine and Hygiene, v. 65, n. 4, p. 329-334, 2001.

5 ROZENTAL, T.; BUSTAMANTE, M. C.; AMORIM, M.; SERRA-FREIRE, N. M.; LEMOS, E. R. S. Evidence of spotted fever group rickettsiae in state of Rio de Janeiro, Brazil. Revista do Instituto de Medicina Tropical de São Paulo, v. 44, n. 3, p. 155-158, 2002.

6 SEXTON, D. J.; MUNIZ, M.; COREY, G. R.; BREITSCHWERDT, E. B.; HEGARTY, B. C.; DUMLER, S.; WALKER, D. H.; PEÇANHA, P. M.; DIETZE, R. Brazilian spotted fever in Espírito Santo, Brazil: description of a focus of infection in a new endemic region. American Journal of Tropical Medicine and Hygiene, v. 49, n. 2, p. 222-226, 1993.

7 PLANK, S. J.; TEIXEIRA, R. S.; MILANESI, M. L. Febre maculosa em Salvador: descrição de um caso. Revista Médica da Bahia, v. 25, p. 330-334, 1979.

8 MADEIRA, A.; WEISBRICH, J. Surto de Febre maculosa no Estado de Santa Catarina. In: CONGRESSO BRASILEIRO DE PARASITOLOGIA VETERINÁRIA, 8.; SIMPÓSIO LATINO-AMERICANO DE RICKETTSIOSES, 1., 2004, Ouro Preto, MG. Anais... Belo Horizonte: Colégio Brasileiro de Parasitologia Veterinária, 2004. p. 364.

9 ANGERAMI, R. N.; RESENDE, M. R.; FELTRIN, A. F. C.; KATZ, G.; NASCIMENTO, E. M.; STUCCHI, R. S. B.; SILVA, L. J. Brazilian spotted fever: a case series from an endemic area in southeastern Brazil - clinical aspects. Annals of New York Academy of Sciences, v. 1078 , p. 252-254, 2006.

10 DIAS, E.; MARTINS, A. V. Spotted fever in Brazil. American Journal of Tropical Medicine, v. 19, p. 103-
108, 1939.

11 GUEDES, E.; LEITE, R. C.; PRATA, M. C. A.; PACHECO, R. C.; WALKER, D. H.; LABRUNA, M. B. Detection of Rickettsia rickettsii in the tick Amblyomma cajennense in a new Brazilian spotted fever-endemic area in the state of Minas Gerais. Memórias do Instituto Oswaldo Cruz, v. 100, n. 8, p. 841-845, 2005.

12 LABRUNA, M. B.; KASAI, N.; FERREIRA, F.; FACCINI, J. L. H.; GENNARI, S. M. Seasonal dynamics of ticks (Acari: Ixodidae) on horses in the state of São Paulo, Brazil. Veterinary Parasitology, v. 105, n. 1, p. 65-77, 2002.

13 SANGIONI, L. A.; HORTA, M. C.; VIANNA, M. C. B.; GENNARI, S. M.; SOARES, R. M.; GALVÃO, M. A. M.; SCHUMAKER, T. T. S.; FERREIRA, F.; VIDOTTO, O.; LABRUNA, M. B. Rickettsial infection in animals and brazilian spotted fever endemicity. Emerging Infectious Diseases, v. 11, n. 2, p. 265-270, 2005.

14 CENTRO DE VIGILÂNCIA EPIDEMIOLÓGICA. Distribuição dos casos confirmados de febre maculosa segundo município provável de infecção no estado de São Paulo: 1985-2006. Disponível em <http:// www.cve.saude.sp.gov.br/htm/zoo/fm_d9803.htm > . Acesso em: 21 jul. 2008.

15 VIEIRA, A. M. L.; SOUZA, C. E.; LABRUNA, M. B.; MAYO, R. C.; SOUZA, S. S. A. L.; CAMARGO-NEVES, V. L. F.; LIMA, V. L. C. Febre maculosa. manual técnico. Disponível em <http://www.sucen.sp.gov.br/doencas/ index.htm >. Acesso em: 21 jul. 2008.

16 MORAES-FILHO, J.; PINTER, A.; PACHECO, R. C.; GUTMANN, T. B.; BARBOSA, S. O.; GONZÁLES, M. A.; MURARO, M. A.; CECÍLIO, S. R.; LABRUNA, M. B. New epidemiological data on Brazilian spotted fever in an endemic area of the state of São Paulo, Brazil. Vector-Borne and Zoonotic Diseases, v. 9, n. 1, p. 7378, 2009.

17 PINTER, A.; HORTA, M. C.; PACHECO, R. C.; MORAES-FILHO, J.; LABRUNA, M. B. Serosurvey of Rickettsia spp. in dogs and humans from an endemic area for Brazilian spotted fever in the State of São Paulo. Cadernos de Saúde Pública, v. 24, n. 2, p. 247-252, 2008.

18 GUGLIELMONE, A. A.; ESTRADA-PEÑA, A.; MANGOLD, A. J.; BARROS-BATTESTI, D. M.; LABRUNA, M. B.; MARTINS, J. R.; VENZAL, J. M.; ARZUA, M.; KEIRANS, J. E. Amblyomma aureolatum (Pallas, 1772) and Amblyomma ovale Kock, 1844: hosts, distribution and $16 \mathrm{~S}$ rDNA sequences. Veterinary Parasitology, v. 113, n. 3/4, p. 273-288, 2003.

19 HORTA, M.C.; LABRUNA, M. B.; SANGIONI, L. A.; VIANNA, M. C. B.; GENNARI, S. M.; GALVÃO, M. A. M.; MAFRA, C. L.; VIDOTTO, O.; SCHUMAKER, T. T. S.; WALKER, D. H. Prevalence of antibodies to spotted fever group rickettsiae in humans and domestic animals in a Brazilian Spotted FeverEndemic area in the state of São Paulo, Brazil: serologic evidence for infection by Rickettsia rickettsii and another spotted fever group Rickettsia. American Journal of 
Tropical Medicine and Hygiene, v. 71, n. 1, p. 93-97, 2004.

20 PINTER, A.; LABRUNA, M. B. Isolation of Rickettsia rickettsii and Rickettsia bellii in cell culture from the tick Amblyomma aureolatum in Brazil. Annals of New York Academy of Sciences, v. 1078, p. 523-529, 2006.

21 LEMOS, E. R. S.; MACHADO, R. D.; COURA, J. R.; GUIMARÃES, M. A. A. M.; GHAGAS, N. Epidemiological aspects of the Brazilian Spotted Fever: Serological survey of dogs and horses in an endemic area in the state of São Paulo, Brazil. Revista do Instituto de Medicina Tropical de São Paulo, v. 38, n. 6, p. 427430, 1996

22 HORTA, M. C.; LABRUNA, M. B.; PINTER, A.; LINARDI, P. M.; SCHUMAKER, T. T. S. Rickettsia infection in five areas of the state of São Paulo, Brazil. Memórias do Instituto Oswaldo Cruz, v. 102, n. 7, p. 793-801, 2007.

23 CARDOSO, L. D.; FREITAS, R. N.; MAFRA, C. L.; NEVES, C. V. B.; FIGUEIRA, F. C. B.; LABRUNA, M. B.; GENNARI, S. M.; WALKER, D. H.; GALVÃO, M. A. M. Caracterização de Rickettsia spp circulante em foco silencioso de febre maculosa brasileira no município de Caratinga, Minas Gerais, Brasil. Cadernos de Saúde Pública, v. 22, n. 3, p. 495-501, 2006. 